\title{
Anomalous Cloquet's canal in a case of optic nervehead coloboma associated with extensive retinal detachment
}

Jun Akiba, Akitoshi Yoshida, Isao Ohta, Hiromasa Igarashi, Akihiro Kakehashi

Department of

Ophthalmology,

Asahikawa Medical

College, Asahikawa,

Japan

J Akiba

A Yoshida

I Ohta

H Igarashi

A Kakehashi

Correspondence to:

Dr J Akiba, Department of Ophthalmology, Asahikawa Medical College, 4-5

Nishikagura, Asahikawa 078, Japan.

Accepted for publication 26 January 1993

Figure 1 Extensive rhegmatogenous retinal detachment associated with optic nervehead coloboma. The central depression of the optic nervehead was covered by a fine, semitranslucent membrane.
Optic nervehead colobomas are rare developmental optic nervehead anomalies sometimes associated with retinal detachment. ${ }^{1}$ In most cases a localised non-rhegmatogenous retinal detachment is found in the posterior pole. ${ }^{24} \mathrm{We}$ managed a case of optic nervehead coloboma associated with extensive rhegmatogenous retinal detachment in which an anomalous Cloquet's canal was observed. To our knowledge this has not been reported previously.

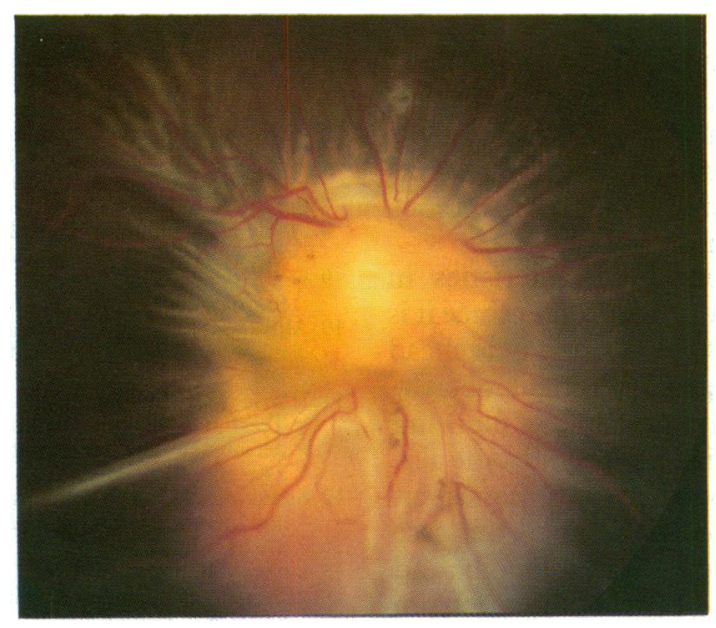

\section{Case report}

In 1985, we examined a 4-year-old boy with suspected strabismus. Examination revealed $10^{\circ}$ esotropia. Corrected visual acuity was 0.2 in the right eye, 1.5 in the left. Slit-lamp examination of both anterior segments was unremarkable. Fundus examination of the right eye revealed an enlarged optic nervehead with upper excavation of the papillary scleral canal that was continuous with a small choroidal coloboma inferiorly, resulting in a diagnosis of optic nervehead coloboma. The left optic nervehead was normal.

Six years later the patient returned complaining of blurred vision in the right eye after being hit in that eye by a soccer ball 2 weeks previously. Best corrected visual acuity was 0.03 in the right eye, 1.5 in the left. The right eye anterior segment was quiet; indirect ophthalmoscopy revealed an extensive retinal detachment (Fig 1), but no retinal breaks. Slit-lamp fundus biomicroscopy with the +90 dioptre preset lens demonstrated that the central depression of the right optic nervehead was covered with a fine, semitranslucent membrane, and that an anomalous Cloquet's canal, the tubular wall of which was condensed remarkably and appeared to be a vitreous strand, terminated at the membrane (Fig 2). No posterior vitreous detachment was found. A whiplash motion of the canal was observed upon ocular movement.

The patient underwent pars plana vitrectomy that included removal of the adherent cortical vitreous and intraocular gas/fluid exchange. A

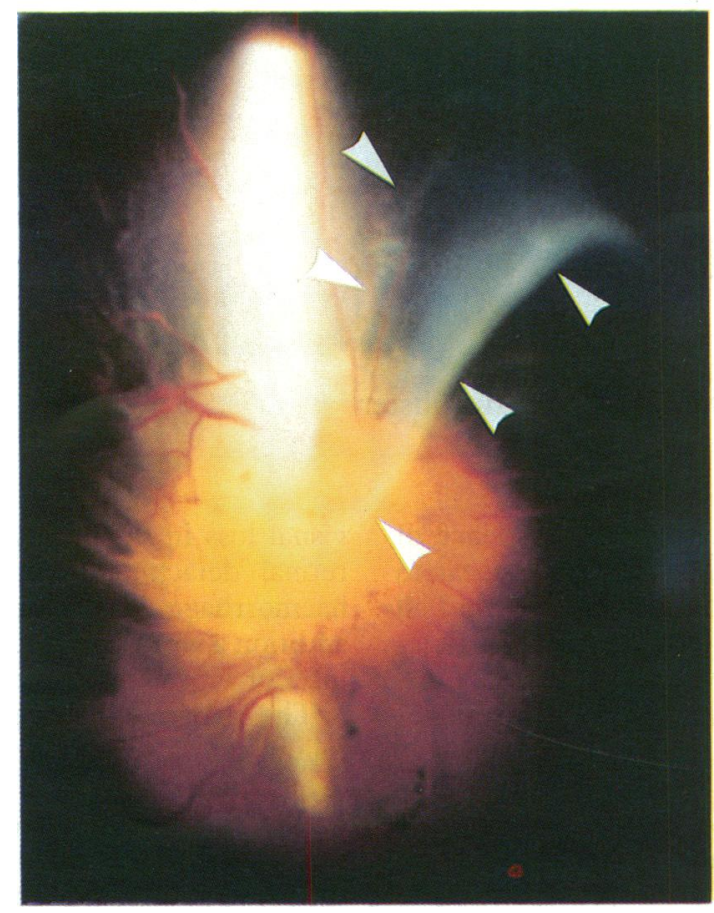

tiny retinal break near the inferior margin of the

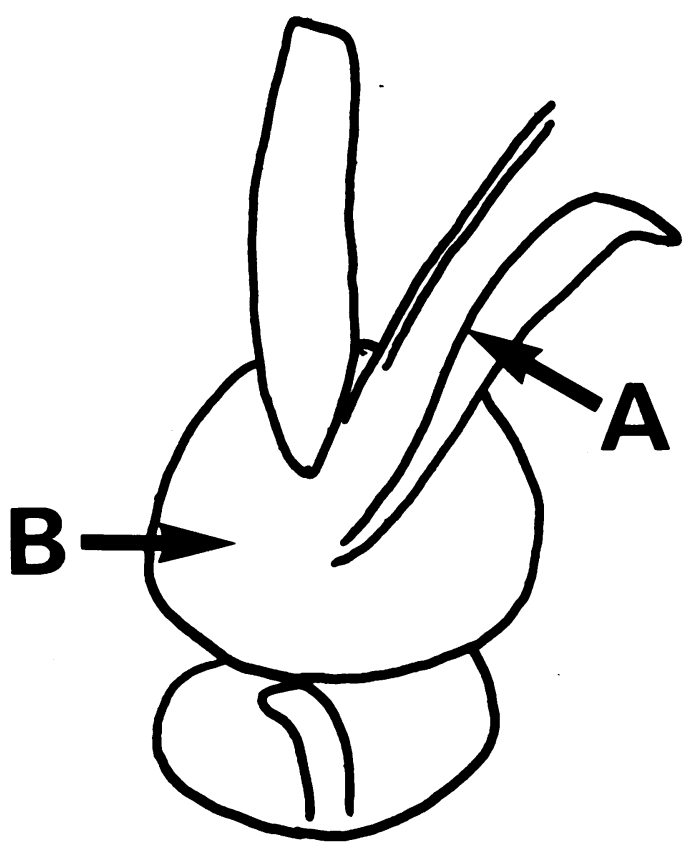

Figure 2 Left, a slit-lamp photograph demonstrating a remarkably condensed Cloquet's canal $(A)$ (arrowheads), which terminated at the membrane covering the central depression of the optic nervehead (B). Right, line drawing of the same eye. 
optic nervehead was treated by endolaser photocoagulation intraoperatively. The retina was completely attached postoperatively. Visual acuity improved to $0 \cdot 1$.

\section{Comment}

Congenital optic nervehead coloboma is believed to reflect defective closure of the embryonic fissure. ${ }^{5}$ Our patient showed a unilateral coloboma inferior of the optic nervehead that was continuous with a small choroidal coloboma. Thus, it is very likely that the embryonic fissure had closed incompletely at an early gestational stage.

We observed a condensed Cloquet's canal that terminated at the membrane covering the central depression of the optic nervehead. A normal Cloquet's canal, which contains the vestiges of primary vitreous, is a tubular structure crossing the vitreous body anteroposteriorly and ending around the optic nervehead margin. ${ }^{6}$ Since the embryonic fissure permits mesodermal tissue to enter the optic cup at an early gestational stage to form a hyaloid artery and primary vitreous, ${ }^{57}$ the anomalous Cloquet's canal, which contains hyperplastic primary vitreous, may terminate at the fine membrane that covers the central depression of the optic nervehead. Thus, we believe that eyes with optic nervehead coloboma may have congenital malformation of the vitreous body and an optic nervehead anomaly.

Our case showed clinical characteristics in keeping with morning glory syndrome, since it is thought to be a specific type of optic nervehead coloboma. ${ }^{8}$ A rhegmatogenous retinal detachment has been observed in some cases of morning glory syndrome. ${ }^{-11}$ Morning glory syndrome also has been reported associated with persistent hyperplastic primary vitreous. ${ }^{12}{ }^{13}$ Thus, our case may illustrate that optic nervehead coloboma and morning glory syndrome are part of the spectrum of congenital optic nervehead anomalies associ- ated with a defective closure of embryonic fissure.

The influence of an anomalous Cloquet's canal on developing retinal detachment is uncertain. Cooling and Feretis ${ }^{14}$ noted the role of vitreoretinal attachment in the genesis of retinal detachment associated with choroidoretinal coloboma. Harris et al ${ }^{11}$ reported a case of extensive rhegmatogenous retinal detachment complicating morning glory syndrome in which a tiny peripapillary retinal break with adjacent vitreous traction was found. Our case showed a tiny retinal break near the optic nervehead and whiplash motion of the anomalous Cloquet's canal. Thus, we speculate that in our case anteroposterior traction on the adjacent retina caused by the whiplash motion of the anomalous Cloquet's canal at the moment of injury may contribute to retinal break formation and subsequent rhegmatogenous retinal detachment.

1 Michels RG, Wilkinson CP, Rice TA. Retinal detachment. St Louis: Mosby, 1990: 152-3.

2 Sugar HS. Congenital pits in the optic disc and their equivalents (congenital colobomas and colobomalike excavations) lents (congenital colobomas and colobomalike excavations) 298-307.

3 Hamada S, Ellsworth RM. Congenital retinal detachment and the optic disk anomaly. Am $\mathcal{F}$ Ophthalmol 1971; 71: 460-4. 4 Savell J, Cook JR. Optic nerve colobomas of autosomaldominant heredity. Arch Ophthalmol 1976; 94: 395-400.

5 Mann I. Developmental anomalies of the eye. 2nd ed. London: British Medical Association, 1957: 113-6.

6 Tolentino FI, Schepens CL, Freeman HM. Vitreoretinal disorders. Philadelphia: Saunders, 1976: 13

7 Sebag J. The vitreous. New York: Springer Verlag, 1989: 8-16.

8 Apple DJ, Rabb MF, Walsh PM. Congenital anomalies of the optic disc. Surv Ophthalmol 1982; 27: 3-41.

9 von Fricken MA, Dhungel R. Retinal detachment in the morning glory syndrome. Retina 1984; 4: 97-9.

10 Akiyama K, Azuma N, Hida T, Uemura Y. Retinal detach ment in morning glory syndrome. Ophthalmic Surg 1984; 15: 841-3.

11 Harris MJ, De Bustros S, Michels RG, Joondeph HC. Treatment of combined traction-rhegmatogenous retinal detachment in the morning glory syndrome. Retina $1984 ; 4$ 249-52.

12 Steinkuller PG. The morning glory disk anomaly: case report and literature review. F Pediatr Ophihalmol Strabismus 1980 17: 81-7.

13 Beyer WB, Quencer RM, Osher RH. Morning glory syndrome. Ophthalmology 1982; 89: 1362-7.

14 Cooling RJ, Feretis EB. Retinal detachment and choroidoretinal coloboma. S Afr Arch Ophthalmol 1983; 10: 9-18.

\title{
Neurocytoma of the retina
}

\author{
Cecily Metcalf, Edward M Mele, Ian McAllister
}

Department of

Pathology, Royal Perth

Hospital

C Metcalf

Department of

Ophthalmology, Royal

Perth Hospital

E M Mele

I McAllister

Correspondence to:

C Metcalf, Department of

Pathology, Royal Perth

Hospital, Box X2213 GPO

Perth, WA 6001, Australia.

Accepted for publication

26 January 1993
Neurocytomas are neoplasms with evidence of neuritic differentiation. Most do not appear to have malignant potential. They are rare and all have been found in the lateral or third ventricles of the brain. To our knowledge, a neurocytoma has not previously been described in the retina.

\section{Case report}

A 67-year-old man presented in April 1991 to the emergency room of a local hospital with acute visual loss in his left eye. A superior temporal retinal detachment with a moderate vitreous haemorrhage was noted on funduscopy. In addition a white elevated lesion was noted on the inferior aspect of the attached retina.

The patient underwent a scleral buckle the following day. Postoperatively a total retinal detachment with an increase in the vitreous haemorrhage was noted and the patient was transferred to our care. Examination confirmed the presence of a total retinal detachment except 